\title{
Serum soluble markers in the evaluation of treatment in human visceral leishmaniasis
}

\author{
A. SCHRIEFER*, A. BARRAL, E. M. CARVALHO \& M. BARRAL-NETTO* Serviço de Imunologia, Hospital \\ Universitário Prof. Edgard Santos, Universidade Federal da Bahia, and * Laboratório Integrado de Microbiologia e \\ Imunorregulaçao, Centro de Pesquisas Gonçalo Moniz, Fundaçáo Oswaldo Cruy, Bahia, Brazil
}

(Accepted for publication 2 August 1995)

\begin{abstract}
SUMMARY
Visceral leishmaniasis (VL) has a fatal course if not properly treated. Recovery from VL is linked to cellular immune response. Unresponsiveness to antimonial therapy reinforces the importance of determining parameters for treatment assessment. We analysed the pre- and post-treatment serum levels of soluble CD4 (sCD4), sCD8, sIL-2R, soluble intercellular adhesion molecule-1 (sICAM-1) and neopterin in groups of VL patients either responsive or not to standard antimonial therapy. Pretreatment serum levels of all markers except for sICAM-1 were significantly higher in VL patients than in healthy subjects from the same area $(P<0 \cdot 05)$. sICAM-1 levels were similar in healthy controls and in VL patients refractory to antimonial therapy $(P=0 \cdot 25)$, but significantly higher in patients responsive to treatment $(P=0.02)$. The comparison of pre- and post-treatment concentrations showed that all markers, except sCD4 and sICAM-1, presented a significant fall $(P<0.05)$ in patients responsive to antimonial therapy. However, only neopterin presented with levels compatible with those of healthy subjects at the end of treatment $(P=0 \cdot 30)$. In refractory patients sICAM-1 presented with post-treatment levels significantly higher than the pretreatment determinations $(P=0.03)$, while sCD4 experienced a significant drop $(P=0.01)$. All markers displayed clearly distinct behaviour according to the patient's response to therapy. This makes all soluble molecules studied suitable for use as indicators of antimonial therapy response. Additionally the comparison of pretreatment levels of the markers between responders and refractory patients to antimonial therapy showed that serum concentrations of sIL-2R and sICAM-1 significantly differed among these two groups $(P=0.02$ in each case), suggesting that they may be used in future as predictors of antimonial therapy response.
\end{abstract}

Keywords visceral leishmaniasis soluble markers antimonial

\section{INTRODUCTION}

American visceral leishmaniasis (VL) is a parasitic disease caused by the protozoan Leishmania chagasi. VL affects millions of people in tropical and subtropical regions of the globe, and has a fatal course if not treated [1,2]. Antimonial compounds, $10-20 \mathrm{mg} / \mathrm{kg}$ per day for 20 days, have been the therapy of choice for decades. Unfortunately, relapses and unresponsiveness to antimonial therapy have been widely reported, resulting in prolonged disease frequently accompanied by life-threatening bacterial infections that further darken the patient's outcome [3-6].

Currently, response to therapy in VL is assessed by clinical and parasitological parameters. Clinical and haematological improvement are highly influenced by the overall condition of

Correspondence: Manoel Barral Netto MD, Hosp. Universitário Prof. Edgard Santos, Serviço de Imunologia, Rua Joao das Botas s/n Canela, 40.110.140 SSA, Bahia, Brazil. the patient, such as nutritional status and coexistence of common causes of chronic blood loss. Splenomegaly may never completely subside in selected cases where portal hypertension evolved [7], and may also be caused by other conditions common in endemic areas of VL. Detection of parasites from splenic aspirates [8] has risks inherent to the procedure and needs experienced professionals to perform it in endemic areas, making its use non-viable for continuous therapeutic evaluation. Furthermore, persistence of VL organisms in treated patients has been reported [9].

In recent years, the concentrations of different soluble molecules in diverse body fluids have been employed as a safe, easy and fast means for the prediction and continuous assessment of therapeutic response in several disorders [9-15]. Such markers are intracellular or cell surface molecules shed into the circulation during the pathogenic process of the disease (e.g. cell activation, cell lysis), and reflect the progress of the underlying condition and the effectiveness of the treatment 
Table 1. Levels of soluble markers of the immune system in the serum of visceral leishmaniasis (VL) patients before and after antimonial therapy

\begin{tabular}{|c|c|c|c|c|c|c|c|c|c|c|}
\hline \multirow{2}{*}{$\begin{array}{l}\text { Patient } \\
\text { no. } \neq\end{array}$} & \multicolumn{2}{|c|}{$\begin{array}{l}\text { sCD4 } \\
(\mathrm{U} / \mathrm{ml})\end{array}$} & \multicolumn{2}{|c|}{$\begin{array}{l}\text { sCD8 } \\
(\mathrm{U} / \mathrm{ml})\end{array}$} & \multicolumn{2}{|c|}{$\begin{array}{l}\text { sIL-2R } \\
\text { (U/ml) }\end{array}$} & \multicolumn{2}{|c|}{$\begin{array}{c}\text { sICAM-1 } \\
(\mathrm{ng} / \mathrm{ml})\end{array}$} & \multicolumn{2}{|c|}{$\begin{array}{l}\text { Neopterin } \\
(\mathrm{nmol} / \mathrm{ml})\end{array}$} \\
\hline & pre & post & pre & post & pre & post & pre & post & pre & post \\
\hline 1 & $22 \cdot 26$ & 6.58 & 1204 & 988 & 3404 & 4456 & 375 & 759 & $11 \cdot 64$ & $17 \cdot 80$ \\
\hline 2 & $34 \cdot 82$ & 17.66 & 1132 & 582 & $>12500 \dagger$ & 8087 & 444 & 800 & $43 \cdot 51$ & $5 \cdot 28$ \\
\hline 3 & $26 \cdot 66$ & $16 \cdot 62$ & 268 & 662 & 4846 & 4362 & 62 & 844 & $29 \cdot 15$ & 8.57 \\
\hline 4 & $31 \cdot 26$ & $18 \cdot 30$ & 2090 & 544 & 5385 & 1465 & 444 & 272 & 95.67 & 3.86 \\
\hline 5 & $21 \cdot 22$ & 10.98 & 1156 & 1206 & 6216 & 5537 & 330 & 692 & $14 \cdot 55$ & $36 \cdot 65$ \\
\hline 6 & $19 \cdot 76$ & $15 \cdot 16$ & 1352 & 1714 & 9334 & 10908 & 311 & 699 & $25 \cdot 41$ & $47 \cdot 74$ \\
\hline 7 & $11 \cdot 80$ & $15 \cdot 16$ & 472 & 794 & 10132 & 3187 & 108 & 336 & $3 \cdot 86$ & $3 \cdot 33$ \\
\hline 8 & $28 \cdot 76$ & $15 \cdot 36$ & 2934 & 658 & $>12500$ & 1418 & ND & ND & $58 \cdot 42$ & 3.40 \\
\hline 9 & $26 \cdot 88$ & $20 \cdot 18$ & 1802 & 2766 & 9864 & $>12500$ & 832 & 826 & $31 \cdot 36$ & $33 \cdot 84$ \\
\hline 10 & ND* & ND & 2162 & 2460 & ND & ND & ND & ND & $33 \cdot 84$ & $65 \cdot 26$ \\
\hline 11 & $22 \cdot 26$ & 17.04 & 1800 & 698 & 12210 & 2356 & 390 & 413 & 8.88 & 4.89 \\
\hline 12 & $10 \cdot 76$ & $15 \cdot 78$ & 1242 & 688 & $>12500$ & 2385 & 1314 & 498 & $25 \cdot 41$ & 4.04 \\
\hline 13 & $14 \cdot 32$ & $16 \cdot 62$ & 688 & 1730 & $>12500$ & $>12500$ & 616 & 673 & ND & ND \\
\hline 14 & $25 \cdot 62$ & $15 \cdot 78$ & 1574 & 690 & 7306 & 2483 & 1092 & 246 & $16 \cdot 89$ & 3.08 \\
\hline 15 & $17 \cdot 46$ & $12 \cdot 02$ & 3156 & 480 & $>12500$ & 5669 & 505 & 310 & $43 \cdot 51$ & 3.08 \\
\hline 16 & $34 \cdot 40$ & $24 \cdot 16$ & 1998 & 764 & $>12500$ & 3688 & 896 & 641 & 52.65 & 5.89 \\
\hline 17 & $24 \cdot 58$ & $20 \cdot 18$ & 2008 & 920 & $>12500$ & $>12500$ & 158 & 0.0 & 95.67 & $5 \cdot 28$ \\
\hline 18 & $37 \cdot 54$ & $15 \cdot 36$ & 1176 & 2058 & 3891 & $>12500$ & ND & ND & $21 \cdot 07$ & $25 \cdot 41$ \\
\hline 19 & $15 \cdot 58$ & 33.98 & 1852 & 552 & $>12500$ & 4286 & 1784 & 368 & ND & ND \\
\hline 20 & ND & ND & 3304 & 926 & ND & ND & ND & ND & 83.40 & $5 \cdot 14$ \\
\hline
\end{tabular}

* ND, Not determined due to insufficient material.

$\dagger>12500$ level was above the detection limit of the test.

$\ddagger$ Patients 1-10 were refractory to antimonials; patients 11-20 were responsive to antimonials.

without necessarily playing an active part in the pathogenic process. Unlike splenic aspirates, the collection of samples for analyses offers minimal risk, and the laboratory techniques, usually ELISAs and radio immunoassays, are fast and require a minimum of training to be reliably performed.

The existence of alternative therapeutic regimens for the treatment of VL cases prompts for the detection of parameters capable of assessing and predicting the ongoing therapeutic response to antimonials in these patients. In the present study, we analysed the serum levels of soluble markers of the immune

Table 2. Levels of statistical significance of the comparisons between serum concentrations of soluble markers in visceral leishmaniasis (VL) patients (before and after antimonial therapy) compared with values from healthy subjects from the same endemic area

\begin{tabular}{lrrrrr}
\hline & \multicolumn{2}{c}{ Responders } & & \multicolumn{2}{c}{ Refractory } \\
\cline { 2 - 3 } \cline { 6 - 6 } Markers & Before & After & & Before & After \\
\hline sCD4 & $<0.01^{*}$ & $<0.01$ & $<0.01$ & $<0.01$ \\
SCD8 & $<0.01$ & 0.01 & & 0.02 & $<0.01$ \\
sIL-2R & $<0.01$ & $<0.01$ & $<0.01$ & $<0.01$ \\
sICAM-1 & 0.02 & 0.05 & & 0.25 & $<0.01$ \\
Neopterin & 0.01 & 0.30 & & 0.01 & 0.03 \\
& & & & & \\
\hline
\end{tabular}

${ }^{*} P$ values obtained from Wilcoxon's rank test, between indicated patient group and normal controls. system thought to be directly or indirectly involved in the pathophysiology of VL. Soluble IL-2 receptor (sIL-2R), sCD4, sCD8 and soluble intercellular adhesion molecule-1 (sICAM-1) and neopterin were evaluated in VL patients, before and after antimonial therapy. sIL-2R has been demonstrated to be a major mediator of the non-specific immunosuppression observed in VL patients [16]. Neopterin is produced by activated phagocytes and its levels have been employed as a marker of phagocyte activation, disease progression and therapeutic response in several conditions [11]. sCD4 and sCD8 have been evaluated due to the potential role of suppressor $\mathrm{T}$ cells in the Leishmania antigen-specific immunosuppression observed during VL [17], and because of reports showing that a relative increase in $\mathrm{CD}^{+}$and decrease in $\mathrm{CD}^{+} \mathrm{T}$ cell subpopulations occur during active disease [1719]. ICAM-1 is an adhesion molecule present on the surface of endothelial cells and fibroblasts [20], whose expression is induced by proinflammatory lymphokines such as interferongamma (IFN- $\gamma$ ) and IL-1 [21,22]. The observations that mononuclear cells of VL patients are unable to secrete IFN- $\gamma$ upon stimulation with leishmanial antigen [23], and human peripheral blood monocytes infected in vitro with $L$. donovani do not secrete IL-1 after challenge with leishmania [24], led us to investigate whether the levels of sICAM-1 in the serum of these patients could give insight into evaluating the outcome of treatment.

The population analysed in this study comprised antimonial responsive and refractory VL patients. The concentrations of each of the above mentioned serum soluble molecules were determined before and after antimony therapy. 

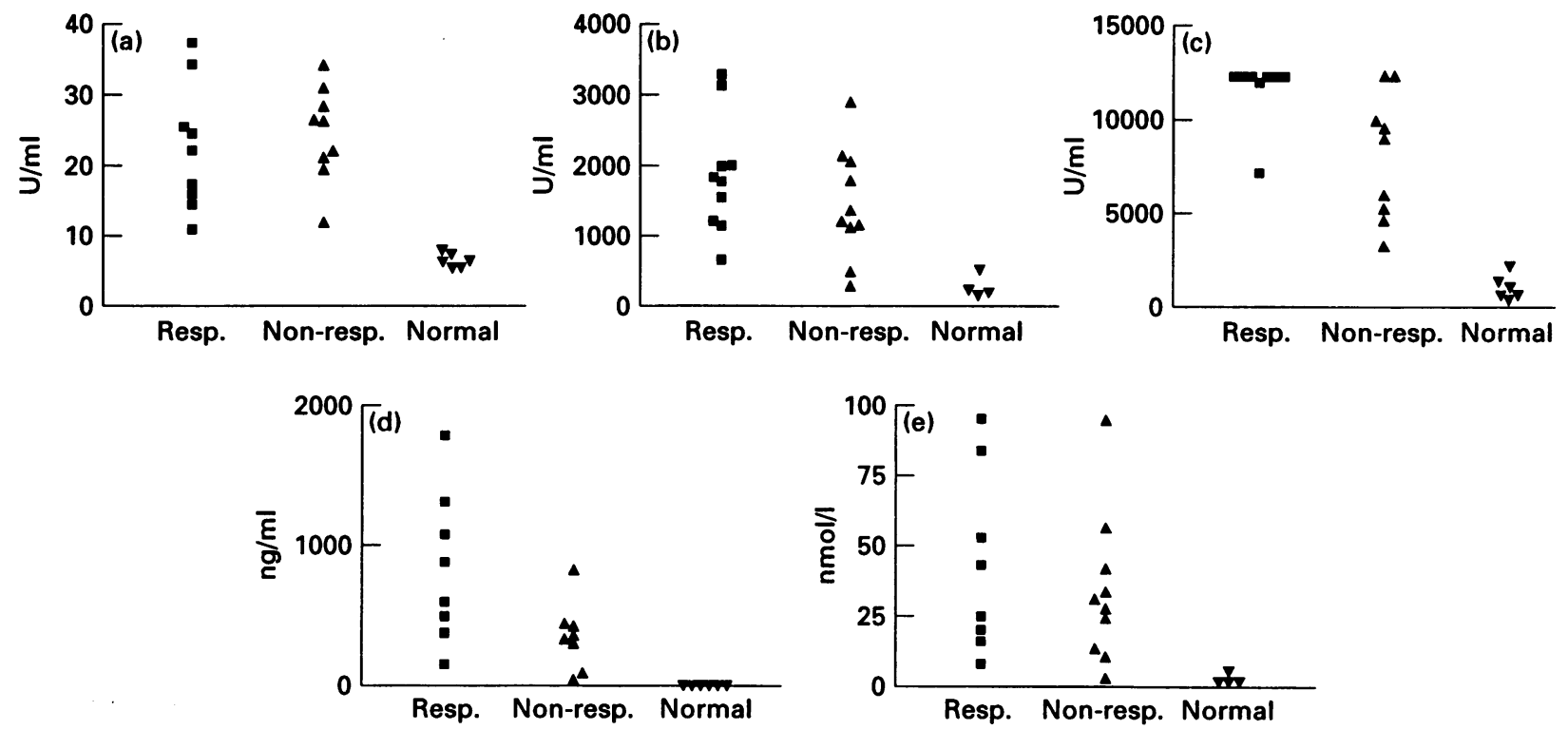

Fig. 1. Levels of soluble (s) CD4 (a), sCD8 (b), sIL-2R (c), soluble intercellular adhesion molecule-1 (sICAM-1) (d) and neopterin (e) in visceral leishmaniasis patients who were later proved to be responsive (Resp.) or refractory (Non-resp.) to antimonial therapy compared with levels of control subjects (Normal) from the same area. Results are means of duplicate determinations of each sample and each point represents a single patient.

\section{PATIENTS AND METHODS}

\section{Patients and groups}

All patients enrolled in the present study came from endemic areas of VL in the state of Bahia, north-eastern Brazil. Clinical diagnosis of VL was confirmed by at least one laboratory test (serology or parasite cultivation). All patients received antimonial therapy. After treatment, each patient was re-evaluated according to the same clinical and laboratory criteria and classified into one of two groups: (i) responsive to antimonial therapy; and (ii) refractory to antimonial therapy. Clinical information regarding study patients has been published elsewhere $[25,26]$.

\section{Sample collection and storage}

Blood samples were collected from each patient before treatment and 30 days post-treatment at the moment of re-evaluation. Serum was collected, aliquoted and frozen at $-20^{\circ} \mathrm{C}$ until tests were performed. Repeated freezing and thawing was avoided by dividing the tests into two batteries, in between which the samples were maintained at $4^{\circ} \mathrm{C}$.

Detection of soluble receptors and neopterin in serum samples Levels of sCD4, sCD8, sIL-2R and sICAM-1 in the serum samples were determined by ELISA ( $T$ Cell Diagnostics, Inc., Cambridge, MA). Serum levels of neopterin were determined by radioimmunoassay (IMMUtest Neopterin; Henning, Berlin, Germany). All tests were conducted as described by the manufacturers. Serum levels of the markers were calculated by interpolating the optical density readings of test samples in standard curves calculated from samples of known concentrations supplied with the kits and assayed in parallel.

Statistical analysis

All statistical analyses performed employed non-parametric tests. Signed Wilcoxon rank test was used in comparisons among individuals of the same group, while Wilcoxon rank test was used in comparisons between different groups. $P<0.05$ was considered significant. The range of normal values for each soluble marker was considered to be that within the limit of $1.96 \mathrm{~s}$.d. of the average concentrations observed in samples of healthy individuals of the same region assayed in parallel.

\section{RESULTS}

Pretreatment serum levels of soluble markers The serum levels of sCD4, sCD8, sIL-2R, sICAM-1 and neopterin in VL patients responsive and refractory to antimonial therapy (as well as normal controls) were determined by ELISA or radioimmunoassay immediately before and after treatment (Table 1). The results of the pretreatment determinations, those of normal controls and the number of samples tested in each group are displayed in Fig. 1. Levels observed in pretreatment samples of VL patients were higher than those in normal controls for all markers (Fig. 1 and Table 2).

Serum concentrations of sCD4, sCD8, sIL-2R, sICAM-1 and neopterin determined before antimonial therapy were compared between responders and refractory VL patients, and the results are listed in Fig. 1 and Table 3. Serum concentrations of sCD4, sCD8 and neopterin did not vary significantly between responders and refractory patients. Pretreatment levels of sIL-2R and sICAM-1 were higher in responders than in refractory patients $(P=0.02$, for both markers). These distinct pre-therapeutic behaviours of sICAM-1 and sIL-2R among VL patients indicate that these markers may prove useful as variables with predictive value on antimonial therapy outcome.

\section{Post-treatment serum levels of soluble markers}

Post-treatment serum levels of sCD4, sCD8, sIL-2R and 
Table 3. Levels of statistical significance of the comparisons between serum concentrations of soluble markers in visceral leishmaniasis (VL) patients responsive and refractory to antimonial therapy

\begin{tabular}{lccc}
\hline Marker & Pre $\times$ pre* & Responders $\dagger$ & Refractory $\dagger$ \\
\hline sCD4 & 0.47 & 0.21 & 0.01 \\
sCD8 & 0.26 & 0.03 & 0.96 \\
sIL-2R & 0.02 & 0.03 & 0.21 \\
sICAM-1 & 0.02 & 0.06 & 0.03 \\
Neopterin & 0.62 & 0.02 & 0.65 \\
\hline
\end{tabular}

* Pretreatment samples from responder patients compared with those from refractory patients by Willcoxon's rank test.

$\dagger$ Comparisons of pre- with post-treatment samples from the same groups by signed Willcoxon's rank test.

sICAM-1 in VL patients were significantly higher than those observed in healthy subjects (Table 2). VL patients responsive to therapy presented with elevated serum levels of neopterin before treatment $(P=0.01)$ and levels compatible with those of healthy subjects after therapy $(P=0 \cdot 3)$. Determinations of neopterin in refractory patients were significantly higher than in the control group both before and after therapy (Table 2).

Progression of soluble marker levels in serum of VL patients The results observed before and after treatment within each group were compared (Fig. 2), and the levels of statistical significance are displayed in Table 3 . This was carried out in an attempt to assess the evolution in serum levels of the studied markers according to the response to antimonial therapy. There was no patient in whom all markers displayed the same evolution (i.e. either raised or dropped), indicating a heterogeneity in the behaviours of these markers. Analysis of Table 3 and Fig. 2 reveals that successful antimonial therapy resulted in a significant drop in the serum levels of SCD8, sIL-2R and neopterin among responders $(P<0.05)$. On the other hand, refractory patients presented a significant drop in sCD4 $(P=0.01)$ and an increase in sICAM-1 $(P=0.03)$. sCD4 and sICAM-1 did not show significant differences between pre- and post-treatment serum levels in responders. sCD8, sIL-2R and neopterin did not change in refractory patients.

\section{DISCUSSION}

The serum levels of several soluble molecules of the immune system were analysed in VL patients responsive or refractory to antimonial therapy. Overall, data for each time point showed a high degree of dispersion in both groups of VL patients. This was not observed among control subjects, suggesting the variation may be due to the underlying condition: (i) the participants enrolled in the study at different stages of disease; and (ii) individual variability of the immune response of patients. The concept of variable clinical courses in VL is further supported by the observations that not all infected individuals develop full blown VL, and that incubation periods may vary widely from a few weeks to years. Non-parametric tests based on median rather than mean concentrations of serum markers were used in order to alleviate the effects of this dispersion in the analysis of data. Paired versions of these tests were used when applicable to decrease even further any bias caused by the dispersion of the data.

Serum levels of all studied markers displayed an outcomespecific evolution, making them suitable for the evaluation of the ongoing treatment. We particularly think that the frequent monitoring of markers that displayed opposite behaviours, like sCD4 and sCD8, would be an easy, objective and safe way of continuously evaluating potential therapeutic failure or success in VL patients undergoing antimonial therapy.

The early normalization of serum levels of neopterin in responders gives it a potential role as indicator of treatment
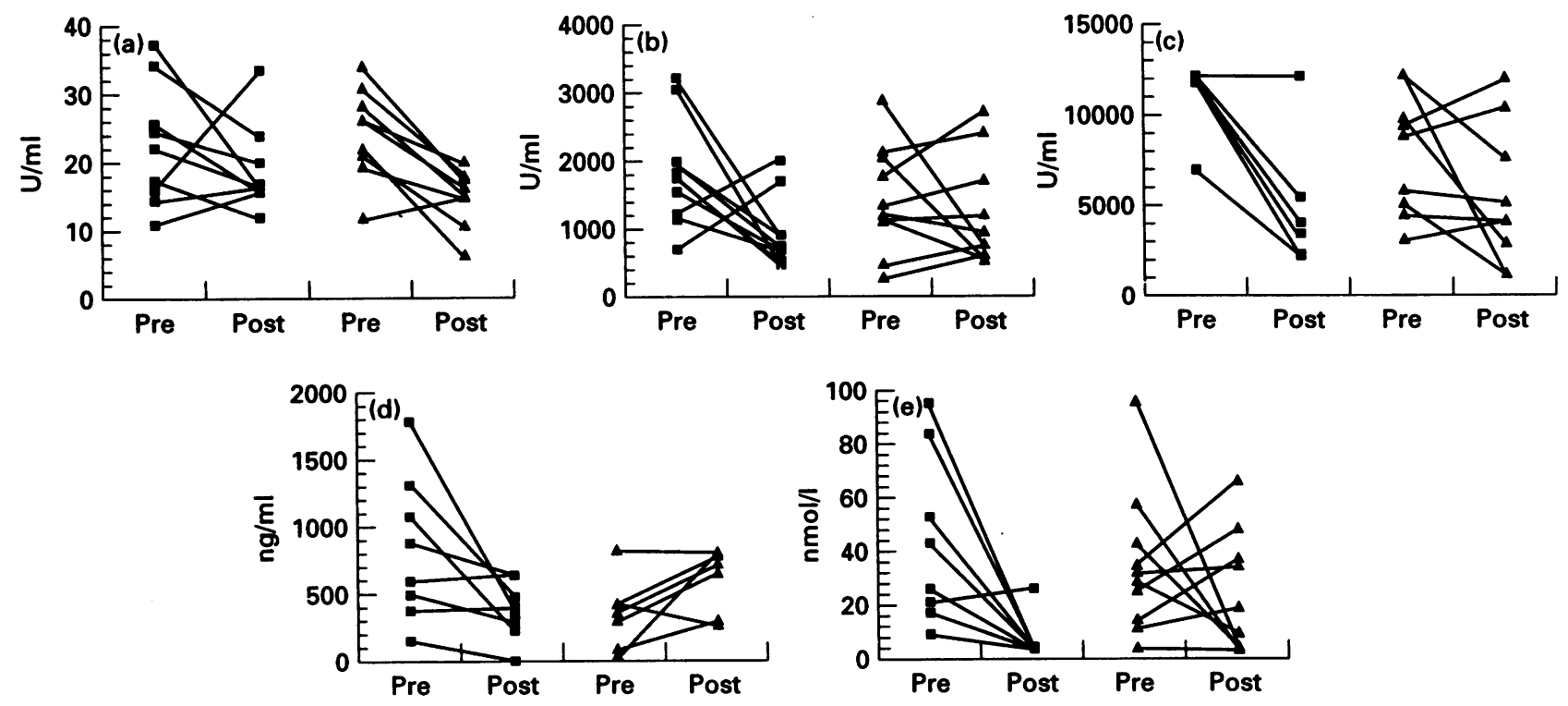

Fig. 2. Pre- and post-treatment serum levels of soluble (s) CD4 (a), sCD8 (b), sIL-2R (c), soluble intercellular adhesion molecule-1 (sICAM-1) (d) and neopterin (e) in visceral leishmaniasis patients who responded $(\boldsymbol{\square})$ or were refractory $(\boldsymbol{\Lambda})$ to antimonial treatment. Pre- (left) and post-treatment (right) levels for each patient are linked by lines. 
success. In analogy to observations in malaria, we believe that the normalization in serum levels of neopterin detected in responsive patients at the end of the treatment course reflects the clearance of parasites from their phagocytic reservoir in the host.

The significant differences observed in pretreatment levels of sIL-2R and sICAM-1 among responder and refractory patients suggest the feasibility of identifying individuals who would most probably benefit from treatment. Larger samples will be needed to trace precisely the threshold between serum concentrations of sIL-2R predictive of therapeutic success or failure, since the concentrations of this marker were significantly elevated in both groups of patients in comparison with normal controls. A possible explanation of the observed association of high pretreatment levels of SIL-2R and SICAM-1 and favourable treatment outcome, would be that these soluble molecules are early indicators of $\mathrm{T}$ cell response and consequent IFN- $\gamma$ production in VL. Activated T cells release sIL$2 \mathrm{R}$ in the circulation [27] and produce IFN- $\gamma$, the major activator of leishmanicidal activity of phagocytes. IFN- $\gamma$ is able to up-regulate ICAM-1 expression [21,22]. So the observations that sIL-2R and sICAM-1 are more elevated in the serum of VL patients that successfully responded than in those that did not respond to antimonial therapy may indicate that the former individuals had a more favourable background to fight the infection, one which was synergized by the treatment. This line of thinking helps resolve the apparent paradox that sIL$2 \mathrm{R}$, the non-specific immunosuppressor observed in the VL patients' serum, and sICAM-1, shed into the circulation during the course of tissue-destructive processes, are not indicative of poorer outcome.

Drops in the levels of tumour necrosis factor-alpha (TNF- $\alpha$ ) [26,28] and of IFN- $\gamma$ and IL-6 [28] have been demonstrated after therapy in VL. To date only sIL-2R has been evaluated in its ability to predict or monitor treatment outcome in VL. Barral-Netto et al. [16] and Vitale et al. [9] showed that the high pretreatment serum levels of this soluble receptor had dropped significantly at the end of successful antimonial therapy, and concluded that sIL-2R could be employed as a marker of disease activity. In the present study we confirmed these observations and extended this analysis to refractory patients. We found that levels of sIL-2R drop during treatment in both groups of patients, although much less markedly in nonresponders. Thus, we think that sIL-2R has the potential to be used as a marker of therapeutic response and for the prediction of treatment outcome. However, as discussed above for the use of sIL-2R levels for prediction of treatment outcome, larger samples must be evaluated for better defining the dropping ratios that would be indicative of good therapeutic response.

\section{ACKNOWLEDGMENTS}

We are grateful to Mrs Silvane Braga and Vera Vinhas for their help in the collection, selection and retrieval of all samples used in this study, and to Mrs Simone Schriefer for helping us in the preparation of the manuscript. We acknowledge Mr Jackson Lemos for secretarial help. This work was supported in part by NIH Grant AI-30639. M. B.-N. is a Senior Researcher of the Brazilian National Research Council (CNPq).

\section{REFERENCES}

1 Marsden PD, Jones TC. Clinical manifestations, diagnosis and treatment of leihmaniasis. In: Chang K-P, Bray RS, eds. Leishmaniasis, Vol. 1 of Ruitenberg EJ, MacInnis AJ, eds. Human parasitic diseases. Amsterdam: Elsevier, 1985: 183-98.

2 Guidelines for Leishmaniasis control at regional and sub regional levels. Geneva: World Health Organization, 1988.

3 Wijers DJB. A ten year' study of kala-azar in Tharaka (Meru District, Kenya). II. Relapses. E Afri Med J 1971; 48:551-88.

4 Bryceson ADM, Chulay JD, Ho $M$ et al. Visceral leishmaniasis unresponsive to antimonial drugs. I. Clinical and immunological studies. Trans R Soc Trop Med Hyg 1985; 79:700-4.

5 Bryceson DM, Chulay JD, Mugambi M et al. Visceral leishmaniasis unresponsive to antimonial drugs. Response to high dosage sodium stibogluconate or prolonged treatment with pentamidine. Trans $\mathbf{R}$ Soc Trop Med Hyg 1985; 79:705-14.

6 Chunge CN, Gachihi G, Muigai R et al. Visceral leishmaniasis unresponsive to antimonial drugs III. Successful treatment using a combination of sodium stibogluconate plus allopurinol. Trans $\mathbf{R}$ Soc Trop Med Hyg 1985; 79:715-8.

7 Pampiglione S, La Place M, Schlick G. Trans R Soc Trop Med Hyg 1974; 68:349.

8 Chulay JD. Bryceson AD. Quantitation of amastigotes of Leishmania donovani in smears of splenic aspirates from patients with visceral leishmaniasis. Am J Trop Med Hyg 1983; 32:475-9.

9 Vitale G, Reina G, Mansueto S et al. The significance of serum soluble IL-2 receptor as a marker for active visceral leishmaniasis in Sicilian patients. Clin Exp Immunol 1992; 90:219-22.

10 Rubin LA, Nelson DL. The soluble interleukin-2 receptor: biology, function, and clinical application. Ann Intern Med 1990; 113:61927.

11 Wachter H, Fuchs D, Hausen A, Reibnegger G, Werner ER. Neopterin as marker for activation of cellular immunity: immunologic basis and clinical application. Adv Clin Chem 1989; 27:81125.

12 Pui $\mathrm{CH}$, Ip S, Thompson E et al. Increased serum CD8 antigen level in childhood Hodgkin's disease relates to advanced stage and poor treatment outcome. Blood 1989; 73:209-13.

13 Ho AD, Grossmann M, Knauf W et al. Plasma levels of soluble CD8 antigen and interleukin-2 receptor antigen in patients with hairy cell leukemia, relationship with splenectomy and with clinical response to therapy. Leukemia $1989 ; 3: 718-23$.

14 Beckham JC, Caldwell DS, Peterson BL, Pippen AMM, Currie MS, Keefe FJ, Weinberg JB. Disease severity in rheumatoid arthritis: relationship of plasma tumor necrosis factor-alpha, soluble interleukin 2-receptor, soluble CD4/CD8 ratio, neopterin, and fibrin DDimer to traditional severity and function measures. J Clin Immunol 1992; 12:353-61.

15 Sfikakis P, Tesar J, Baraf H, Lipnick R, Klipple G, Tsokos GC. Circulating intercellular adhesion molecule-1 in patients with systemic sclerosis. Clin Immunol Immunopathol 1993; 68:88-92.

16 Barral-Netto M, Barral A, Santos SB et al. Soluble IL-2 receptor as an agent of serum-mediated suppression in human visceral leishmaniasis. J Immunol 1991; 147:281-4.

17 Carvalho EM, Bacellar O, Barral A, Badaró R, Johnson Jr WD. Antigen-specific immunosuppression in visceral leishmaniasis is cell mediated. J Clin Invest 1989; 83:860-4.

18 Koech DK. Subpopulations of T lymphocytes in Kenyan patients with visceral leishmaniasis. Am J Trop Med Hyg 1987; 36:497-500.

19 Sciotto A, Russo-Mancuso G, Zinna CM, Comisi F, Sciannaca RM, Schiliro G. Lymphocyte subsets in Kala-Azar. Ann Allergy 1989; 63:343-6.

20 Springer TA. Adhesion receptors of the immune system. Nature 1990; 346:425-34.

21 Dustin ML, Rothlein R, Bhan AK, Dinarello CA, Springer TA. Induction by IL-1 and interferon-gamma: tissue distribution., biochemistry, and function of a natural adherence molecule (ICAM-1). J Immunol 1986; 137:245-54.

22 Rothlein R, Czajkowski M, O'Neill M, Marlin SD, Mainolfi E,

(C) 1995 Blackwell Science Ltd, Clinical and Experimental Immunology, 102:535-540 
Merluzzi VJ. Induction of intercellular adhesion molecule 1 on primary and continuous cell lines by pro-inflammatory cytokines. Regulation by pharmacologic agents and neutralizing antibodies. $\mathrm{J}$ Immunol 1988; 141:1665-9.

23 Carvalho EM, Badaró R, Reed SG, Jones TC, Johnson Jr WD. Absence of gamma interferon and interleukin 2 production during active visceral leishmaniasis. J Clin Invest 1985; 76:2066-9.

24 Reiner NE, Ng W, Wilson CB, McMaster WR, Burchett SK. Modulation of in vitro monocyte cytokine responses to Leishmania donovani. Interferon-gamma prevents parasite-induced inhibition of interleukin 1 production and primes monocytes to respond to leishmania by producing both tumor necrosis factor-alpha and interleukin 1. J Clin Invest 1990; 85:1914-24.

25 Carvalho EM, Barral A, Pedral-Sampaio D, Barral-Netto M,
Badaró R, Rocha H, Johnson Jr WD. Immunologic markers of clinical evolution in children recently infected with Leishmania donovani chagasi. J Infect Dis 1992; 165:535-40.

26 Barral-Netto M, Badaró R, Barral A et al. Tumor necrosis factor (cachectin) in human visceral leishmaniasis. J Infec Dis 1991; 163:853-7.

27 Rubin LA, Kurman C, Fritz ME, Biddison WE, Boutin B, Yarchoan R, Nelson DL. Soluble interleukin 2 receptors are released from activated human lymphoid cells in vitro. $\mathrm{J}$ Immunol $1985 ; 135: 3172-7$

28 Cenini P, Berhe N, Hailu A, McGinnes K, Frommel D. Mononuclear cell subpopulations and cytokine levels in human visceral leishmaniasis before and after chemotherapy. J Infec Dis 1993; 168:986-93. 